\title{
Ferramentas interativas de apoio à Educação Corporativa a Distância
}

Michelle Pinheiro, Janine De Lavechia,

Raquel Rodrigues,

Márcio Vieira de Souza

\section{INTRODUÇão}

$\mathrm{Na}$ era do conhecimento, a educação apresenta-se em diversos tipos de organizações, além das instituições de ensino. Como exemplo desse contexto, as empresas estão investindo com força na capacitação de seus profissionais, buscando abrir vantagem competitiva sobre seus concorrentes. As tecnologias estão a cada dia sendo inseridas no cotidiano das pessoas, assim, fazendo com que as empresas também se adaptem a novos métodos de aprendizagem.

Segundo Carvalho (2014), o uso crescente de Tecnologias da Informação e Comunicação (TIC) na educação proporcionam uma variedade de aplicações, seja em cursos totalmente presenciais, seja em cursos com encontros presenciais, chamados de mistos, ou em cursos totalmente a distância, que permitem a criação de ambientes híbridos, que podem enriquecer o processo de ensino e aprendizagem.

A Educação a Distância (EaD) não se limita apenas às instituições de ensino, podendo estar vinculada às organizações, o que possibilita desenvolver novas habilidades de seus colaboradores, na chamada Educação Corporativa (EC). Para Alencar (2012, p. 1) "as corporações investem valores expressivos na educação corporativa com o objetivo de manter qualificados os atuais colaboradores, bem como auxiliar na preparação dos novos".

A partir desse contexto, elaborou-se o seguinte questionamento: quais ferramentas auxiliam a oferta da Educação Corporativa (EC) na modalidade a distância? Na tentativa de responder tal pergunta, o presente artigo tem como objetivo apresentar uma revisão sistemática sobre o tema educação corporativa a distância, com foco em um levantamento sobre as ferramentas de apoio ao ensino a distância na educação corporativa, através da técnica de bibliometria. 


\section{EDUCAÇÃO CORPORATIVA}

A Educação Corporativa (EC) surgiu nos Estados Unidos na década de 1950, quando empresas, visando à liderança do mercado, alavancaram esse movimento para alcançar a vantagem competitiva (QUARTIERO; CERNY, 2005). Já no Brasil, a EC aparece na década de 90, num quadro de abertura econômica do país, que impulsionou a ideologia da competição para o mercado globalizado (MARTINS, 2004).

Esse ambiente de constantes mudanças favoreceu uma gestão flexível nas organizações, acarretando o desenvolvimento de pessoas com autonomia, iniciativa e dinamismo, voltadas para o autodesenvolvimento e para a aprendizagem contínua (EBOLI, 2004).

Segundo uma das precursoras desse movimento, Meister (1999), o modelo de EC é sustentado por cinco grandes forças do cenário global: (i) o surgimento da educação por processos, horizontalizada e flexível; (ii) a emergência da gestão do conhecimento; (iii) a volatilidade da informação e a obsolescência do conhecimento; (iv) o foco na empregabilidade: educar para o trabalho, não para o emprego; e (v) a mudança no foco da educação geral. A EC é definida como um "guarda-chuva estratégico para o desenvolvimento e a educação de funcionários, clientes e fornecedores, buscando otimizar as estratégias organizacionais, além de um laboratório de aprendizagem para a organização e um polo de educação permanente" (MEISTER, 1999, p. 8).

Para o Ministério de Desenvolvimento Indústria e Comércio Exterior "é mais do que treinamento empresarial ou qualificação de mão-de-obra. Trata-se de articular coerentemente as competências individuais e organizacionais no contexto mais amplo da empresa". Assim, as práticas de educação corporativa estão diretamente relacionadas à inovação nas empresas e ao aumento da competitividade de seus bens ou serviços (BRASIL, 2016).

Ressalta-se que a educação corporativa não se caracteriza por um conjunto de cursos e programas de treinamento e desenvolvimento oferecidos pelas organizações de forma desarticulada. O fundamental do conceito é que existe um objetivo maior que integra todas as ações educacionais (REIS; SILVA; EBOLI, 2010, p. 407).

Eboli (2004) definiu sete princípios de sucesso de um sistema de educação corporativa, conforme mostrado no Quadro 1. 


\begin{tabular}{|c|c|}
\hline $\begin{array}{l}\text { Princípio nำ: } \\
\text { Competitividade }\end{array}$ & $\begin{array}{l}\text { Valorizar a Educação como forma de desenvolver o } \\
\text { capital intelectual dos colaboradores, transformando-os } \\
\text { efetivamente em fator de diferenciação da empresa diante } \\
\text { dos concorrentes, ampliando, assim, sua capacidade de } \\
\text { competir. Significa buscar continuamente elevar o patamar } \\
\text { de competitividade empresarial por meio da implantação, } \\
\text { desenvolvimento e consolidação das competências críticas } \\
\text { empresariais. }\end{array}$ \\
\hline $\begin{array}{l}\text { Princípio no 2: } \\
\text { Perpetuidade }\end{array}$ & $\begin{array}{l}\text { Entender a educação não apenas como um processo de } \\
\text { desenvolvimento e realização do potencial existente em cada } \\
\text { colaborador, mas também como um processo de transmissão } \\
\text { de herança cultural, a fim de perpetuar a existência da } \\
\text { empresa. }\end{array}$ \\
\hline $\begin{array}{l}\text { Princípio no 3: } \\
\text { Conectividade }\end{array}$ & $\begin{array}{l}\text { Privilegiar a construção social do conhecimento, } \\
\text { estabelecendo conexões e intensificando a comunicação e } \\
\text { a interação. Objetiva ampliar a quantidade e a qualidade da } \\
\text { rede de relacionamentos com o público interno e externo. }\end{array}$ \\
\hline $\begin{array}{l}\text { Princípio no 4: } \\
\text { Disponibilidade }\end{array}$ & $\begin{array}{l}\text { Oferecer e disponibilizar atividades e recursos educacionais } \\
\text { de fácil uso e acesso, propiciando condições favoráveis para } \\
\text { que os colaboradores realizem a aprendizagem a qualquer } \\
\text { hora e em qualquer lugar. }\end{array}$ \\
\hline $\begin{array}{l}\text { Princípio no 5: } \\
\text { Cidadania }\end{array}$ & $\begin{array}{l}\text { Estimular o exercício da cidadania individual e corporativa, } \\
\text { formando atores sociais, ou seja, sujeitos capazes de refletir } \\
\text { criticamente sobre a realidade organizacional, de construí- } \\
\text { la e modificá-la, e de atuar pautados por postura ética e } \\
\text { socialmente responsável. }\end{array}$ \\
\hline $\begin{array}{l}\text { Princípio no 6: } \\
\text { Parceria }\end{array}$ & $\begin{array}{l}\text { Entender que desenvolver continuamente as competências } \\
\text { dos colaboradores é uma tarefa complexa, exigindo que se } \\
\text { estabeleçam parcerias internas (com líderes e gestores) e } \\
\text { externas (instituições de nível superior). }\end{array}$ \\
\hline $\begin{array}{l}\text { Princípio no 7: } \\
\text { Sustentabilidade }\end{array}$ & $\begin{array}{l}\text { Ser um centro gerador de resultados para a empresa, } \\
\text { procurando sempre agregar valor ao negócio. Pode significar } \\
\text { também buscar fontes alternativas de recursos que } \\
\text { permitam um orçamento próprio e autossustentável. }\end{array}$ \\
\hline
\end{tabular}

Quadro 1 - Os sete princípios de sucesso de um sistema de educação corporativa Fonte: Eboli (2004 p. 20-22).

A autora supracitada associa práticas a cada um dos princípios, e é importante destacar às do princípio "Disponibilidade" para: utilizar de forma intensiva tecnologia aplicada à educação; implantar projetos virtuais de educação 
(aprendizagem mediada por tecnologia); implantar múltiplas formas e processos de aprendizagem que favoreçam a "aprendizagem a qualquer hora e em qualquer lugar”.

De acordo com os dados da $3^{\text {a }}$ Pesquisa Nacional de Práticas e Resultados em Educação Corporativa, da Fundação Instituto de Administração (EBOLI, 2015), aplicada a empresas de setores diversificados, mesmo com a crise, do total de respondentes $(=95)$, quase a metade $(=43$ ou $45 \%)$ aumentou o investimento em EC. Os principais motivos são a expansão da empresa e a necessidade estratégica. Dos respondentes, destacaram-se as organizações privadas e de capital nacional. As principais tendências apontadas em educação corporativa para os próximos cinco anos foram: desenvolvimento de liderança, EaD, aprendizagem colaborativa, trilhas de aprendizagem e avaliação e mensuração de resultados. Já com relação aos desafios, o mais apontado foi a "atuação estratégica", seguido da "avaliação e mensuração de resultados" e da "promoção do autodesenvolvimento dos colaboradores".

Com o surgimento de novas mídias interativas, viram-se mais projetos voltados para a Educação Corporativa a Distância, recurso cada vez mais difundido nas organizações (SILVA, 2010).

\section{FERRAMENTAS UTILIZADAS NA EDUCAÇÃO CORPORATIVA A DISTÂNCIA}

A tecnologia digital atualmente é um requisito indispensável no contexto das organizações. Os recursos tecnológicos digitais estão presentes em diversas áreas, em uma era tecnológica que trouxe diversos benefícios para a aprendizagem, e as tecnologias estão sendo cada vez mais utilizadas na Educação Corporativa (MONTEIRO; MÜRI, 2014).

Existem vários ambientes e ferramentas de apoio à aprendizagem na modalidade a distância. Com isso, as organizações vêm investindo e avaliando a Educação Corporativa como um espaço institucional voltado para o desenvolvimento e produção de alternativas educacionais sintonizadas com suas necessidades. Assim, é relevante citar algumas soluções de ambientes de apoio à aprendizagem no processo de ensino a distância, como exemplo: TelEduc (é um ambiente de e-learning para a criação, participação e administração de cursos na Web), VIAS Knowledge (ambiente virtual de aprendizagem), Web ensino (ambiente virtual de aprendizagem da Educação a Distância), Blackboard (ferramentas de aprendizagem), entre outros (ABREU; GONÇALVES; PAGNOZZI, 2003).

Conforme exposto na Figura 2, o gráfico mostra dados da $3^{\text {a }}$ Pesquisa Nacional Práticas e Resultados da Educação Corporativa (2015), que ilustra o per- 
centual de tecnologias utilizadas em programas de EaD e incluiu um total de 95 organizações que responderam a pesquisa. Das empresas respondentes, aproximadamente $87 \%$ utilizam o Ambiente Virtual de Aprendizagem (AVA) como uma tecnologia para aprendizagem a distância e podem agregar a utilização de outras tecnologias simultaneamente.

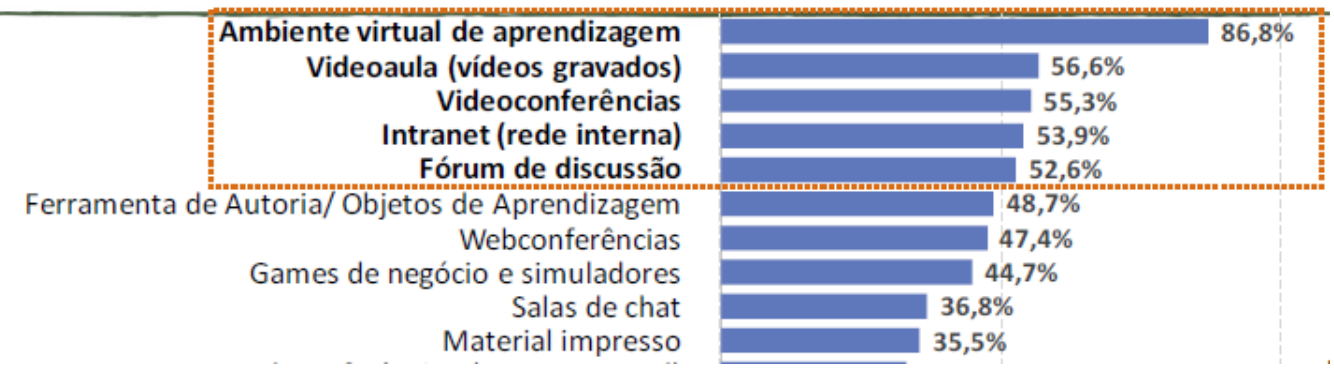

Figura 2 - Práticas de Educação a Distância (EaD)

Fonte: Eboli (2015).

Na próxima seção, são apresentados alguns processos educacionais que utilizam recursos digitais una EC, bem como são descritos aspectos fundamentais e formas de aprendizagem que demostram a utilização dessas ferramentas como auxiliares na educação corporativa a distância.

\subsection{E-LEARNIG}

A educação a distância e o e-learning, apesar de serem modalidades de ensino não necessariamente presenciais, abrangem aplicações diferentes. Segundo Fernandes (2013, p. 3), “[...] o que difere uma da outra é a sua aplicação. Enquanto o e-learning é transmitido apenas por meios eletrônicos e tecnológicos, a $\mathrm{EaD}$ se dá tanto por ferramentas impressas quanto eletrônicas e tecnológicas".

Assim, em um sentido de complementariedade de contextos, Monteiro e Müri (2014) defendem que o e-learning é uma modalidade de educação a distância por meio das tecnologias, em que os professores e os alunos estão interligados através da internet, mas separados por espaço e por tempo.

No e-learning, as etapas de ensino estão pré-programadas e são utilizadas em diversos recursos como o e-mail, textos e imagens digitalizadas, sala de bate-papo, links para fontes externas, vídeos e teleconferências, entre outros (CASTRO; VALENTE; HUDIK, 2011). Uma das vantagens da utilização do e-learning é o rompimento de barreiras geográficas e temporais, já que esse tipo de aprendizagem possibilita o aluno gerenciar tempo de estudo disponível, através 
dos parâmetros estabelecidos pelo curso, sem precisar estar se locomovendo. Com essas vantagens, o e-learning apresenta-se como é uma das metodologias mais utilizadas pelas empresas que desenvolvem a educação corporativa (CASTRO; VALENTE; HUDIK, 2011).

\subsection{DIGITAL STORYTELLING}

Digital Storytelling em seu conceito mais básico é a prática de utilizar ferramentas informatizadas para contar histórias. Há muitos outros termos para descrever essa prática, como documentários digitais, narrativas baseadas em computador, ensaios digitais, memórias eletrônicas, narrativa interativa, entre outas; sendo que todas giram em torno da ideia de combinar a arte de contar histórias com uma variedade de arte multimídia, incluindo gráficos, áudio, vídeo e publicação na web (ROBIN, 2004).

Para Monteiro e Müri (2014, p. 54), “o Digital Storytelling pode ser um poderoso instrumento educativo em razão dos inúmeros benefícios que a sua utilização pode trazer”. Também, Hack, Ramos e Santos (2013, p. 5) afirmam que "a utilização de histórias digitais em processos de formação de adultos pode oferecer uma oportunidade para a promoção de interações múltiplas (colaborações) no processo de construção do conhecimento".

Para Hack, Ramos e Santos (2013) o Digital Storytelling propõe outras formas de utilização das histórias contadas em formato digital no contexto corporativo, seja para:

Comunicação da missão da empresa;

Objetivos e políticas corporativas;

Mobilização e fomentação do espírito de equipe;

Envolvimento das pessoas em determinadas ações estratégicas;

Estruturação e divulgação da memória corporativa;

Fortalecimento dos valores e traços característicos da corporação.

Finalmente, avalia-se que o Digital Storytelling é uma técnica com enorme potencial de aprendizagem no ambiente corporativo, pois com o aumento das tecnologias na educação, tem tudo para ser cada vez mais utilizada pelas empresas (MONTEIRO; MÜRI, 2014).

\subsection{TECNOLOGIA WIKI}

Uma das tecnologias utilizadas no ambiente corporativo em destaque é a Wiki. Pois, se traduz em uma ferramenta utilizada para a disseminação de infor- 
mações na $\mathrm{EaD}$, necessitando de pesquisas na área, visto que seu uso na educação é recente (ALVES; SCORSOLINI-COMIN, 2012).

A tecnologia Wiki é uma ferramenta utilizada via internet que tem a possibilidade de construção aberta e coletiva do conhecimento. Segundo Bomfim e Gonçalves (2015, p. 7):

Trata-se de uma tecnologia que possibilita a mistura de diversos recursos como a palavra, a imagem (estática ou em movimento), o som, a animação etc., bem como as ligações internas e externas, oferecendo os recursos básicos para a produção de textos para o contexto digital (hipertextos).

Para D’Andréa (2009, p. 13), “Wikis são softwares com características técnicas específicas e passíveis de apropriação com diferentes finalidades, como a gestão de informação em empresas e aprendizagem colaborativa em escolas e outros contextos educacionais". Assim, a tecnologia Wiki pode ser definida como software online que, através de páginas da web, possui o objetivo de realizar a criação colaborativa e coletiva de conteúdos.

\subsection{REDES SOCIAIS}

As comunidades de redes sociais online vêm ganhando espaço e estão gerando mudanças na forma de relacionamento entre as pessoas, e também, alterando a maneira como as informações são compartilhadas no dia a dia. Segundo Gulini e Misaghi (2012, p. 45), o uso de redes sociais "nos últimos anos chamou a atenção de muitas empresas que passaram a adotar esta nova forma de relacionamento, promovendo o compartilhamento de informações e a colaboração no ambiente corporativo".

Para Monteiro e Müri (2014), as redes sociais permitem a comunicação não hierárquica e que possibilita também o reconhecimento de talentos dentro da organização, pois permite identificar quem conhece e resolve problemas. Nesse sentido, Gulini e Misaghi (2012, p. 51) explanam sobre as áreas de atuação das redes sociais:

[...] podem ser aproveitadas pelas organizações em diversas áreas. $\mathrm{Na}$ área de recursos humanos, por exemplo, tem-se uma maior facilidade de identificar líderes ou necessidades de treinamento e desenvolvimento. Gestão do Conhecimento, Colaboração e Inovação também são alguns benefícios que podem ser destacados com a utilização das redes sociais corporativas. 
Para Ferla (2012) a rede social, no âmbito corporativo, amplia a comunicação interna das empresas e cria um ambiente em que o colaborador pode compartilhar seu conhecimento e ampliar o relacionamento com os colegas de trabalho, oferecendo os mesmos recursos de uma rede social comum, tais como as redes Facebook e Twitter, em que se pode criar perfis, grupos, feed de notícias em formato timeline (linha do tempo), chat, grupos temáticos, páginas, opções para "curtir" e compartilhar conteúdo, entre outros, representando uma maneira fácil de criar um ambiente de colaboração e de gestão do conhecimento. A autora supracitada destaca, ainda, uma importante diferença entre a rede social corporativa e uma rede social comum: a facilidade de desenvolvimento e poder de customização, conforme as necessidades de cada empresa.

\section{PROCEDIMENTOS METOdOLÓGICOS}

De natureza exploratória, esta pesquisa utilizou-se de método de revisão sistemática da literatura (RSL) em bases de dados online, seguida de uma análise bibliométrica.

Conforme Freire (2013, p. 30), “a RSL é um processo de levantamento de dados em que são exigidas revisões rigorosas de publicações acadêmicas à procura de indícios que possam levar à identificação de evidências sobre um tema de pesquisa ou tópico na área pretendida". Já a bibliometria é um tipo de análise resultante de uma RSL, "é um método flexível para avaliar a tipologia, a quantidade e a qualidade das fontes de informação citadas em pesquisas”. (SILVA; HAYASHI; HAYASHI, 2011, p. 113).

Com a definição da questão da pesquisa "Quais ferramentas auxiliam a EC na modalidade a distância?”, recorreu-se à base de dados de consulta online Scopus para buscar as publicações relacionadas ao escopo da pesquisa. Freire (2010, p.45) afirma que "a base Scopus é hoje a maior base de resumos e referências bibliográficas de literatura científica, revisada por pares, permitindo uma visão multidisciplinar e integrada de fontes relevantes para a pesquisa bibliográfica sistemática”.

A pesquisa realizou-se no mês de agosto de 2016, utilizando os seguintes termos e operadores booleanos como estratégia de busca na base Scopus: "Corporate education" AND “Distance” OR “Online”. A base recuperou 15 (quinze) documentos sendo 10 (dez) artigos, 1 (um) artigo impresso, 1 (um) conference paper, 1 (um) livro e 2 (dois) capítulos de livros. Importante ressaltar que não houve aplicação de filtros.

Realizando a leitura dos títulos, palavras-chave e resumos das publicações encontradas, confirmou-se que os 15 documentos estavam alinhados ao tema de 
pesquisa. Na sequência, a próxima seção apresenta os resultados da bibliometria dos estudos selecionados, bem como discussão e análise desta investigação.

\section{RESULTADOS}

Nessa seção, com o intuito de identificar a evolução e a área do conhecimento das publicações, autores e países com maior produção, tipo de documento predominante, deu-se sequência à análise bibliométrica das publicações do escopo da pesquisa.

No que se refere à análise dos resultados, verificou-se que os estudos sobre o tema "educação corporativa online", na base Scopus, tem seu primeiro registro em 2003, com a publicação de um livro dos autores Thomas M. Duffy e Jamie Reaves Kirkley, nos Estados Unidos.

Observa-se que a maioria dos estudos foram publicados entre os anos de 2012 e 2016, com três publicações em cada ano, representando 40\% de estudos selecionados na pesquisa, como ilustra o Gráfico 1.

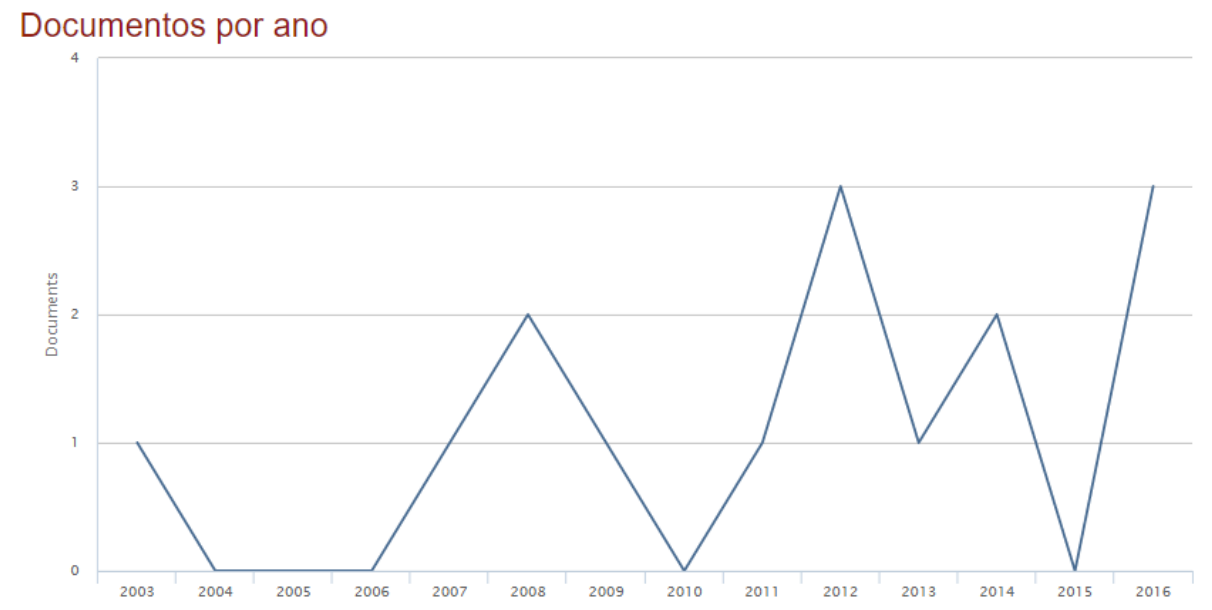

Gráfico 1 - Anos das Publicações

Fonte: Dados da pesquisa.

De acordo com a análise geográfica, o Gráfico 2 apresenta os países que mais contribuíram com o tema. Esses países foram o Brasil e os Estados Unidos, com o total de três documentos cada, representando $40 \%$ do escopo de pesquisa. $\mathrm{Na}$ sequência, aparecem França, Rússia e Sérvia, cada país com duas publicações. 


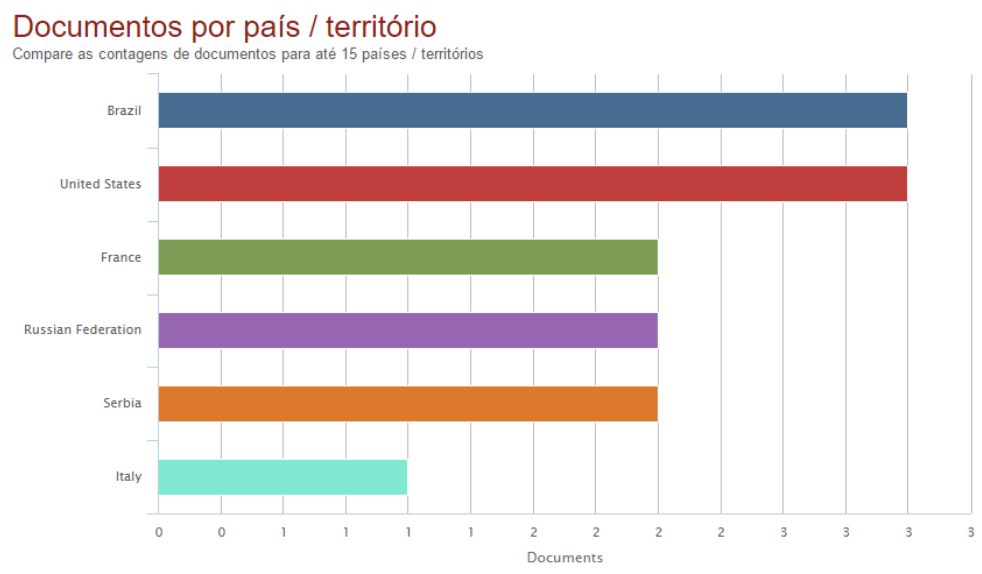

Gráfico 2 - Países das Publicações

Fonte: Dados da pesquisa.

O tipo de documento predominante localizado nas buscas foi de artigo, em um total de dez itens, que corresponde a $66,7 \%$ do total das publicações, seguido pelos capítulos de livros, com representação de dois itens, conforme ilustrado no Gráfico 3.

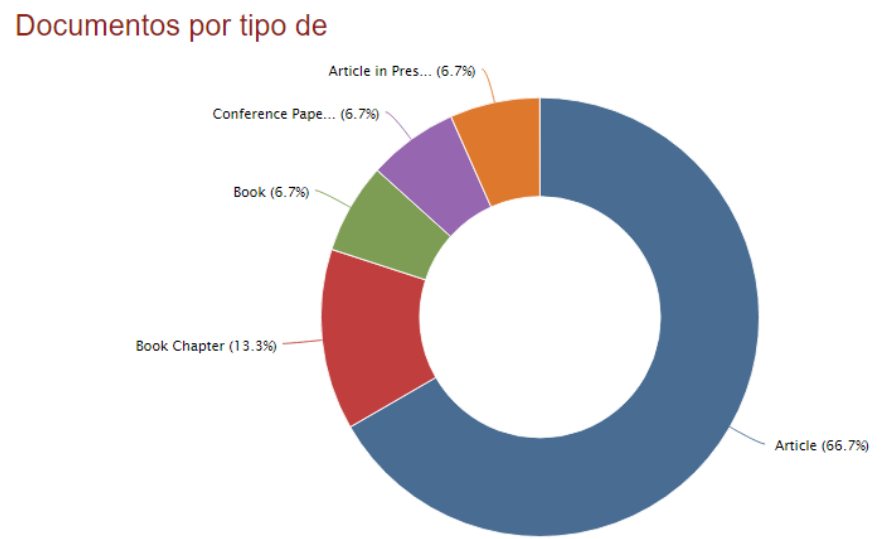

Gráfico 4 - Tipo de documento

Fonte: Dados da pesquisa.

Devido ao aspecto multidisciplinar da base, é perceptível na ilustração do Gráfico 4 a abrangência em diferentes áreas de estudo, considerando o aspecto interdisciplinar do tema. Ainda assim, a área com maior concentração na pesquisa foi a de Ciências Sociais com nove documentos, o que equivale a $60 \%$ do total, seguida da área de Negócios, Gestão e Contabilidade com 33,3\%. 
Documentos por área de assunto

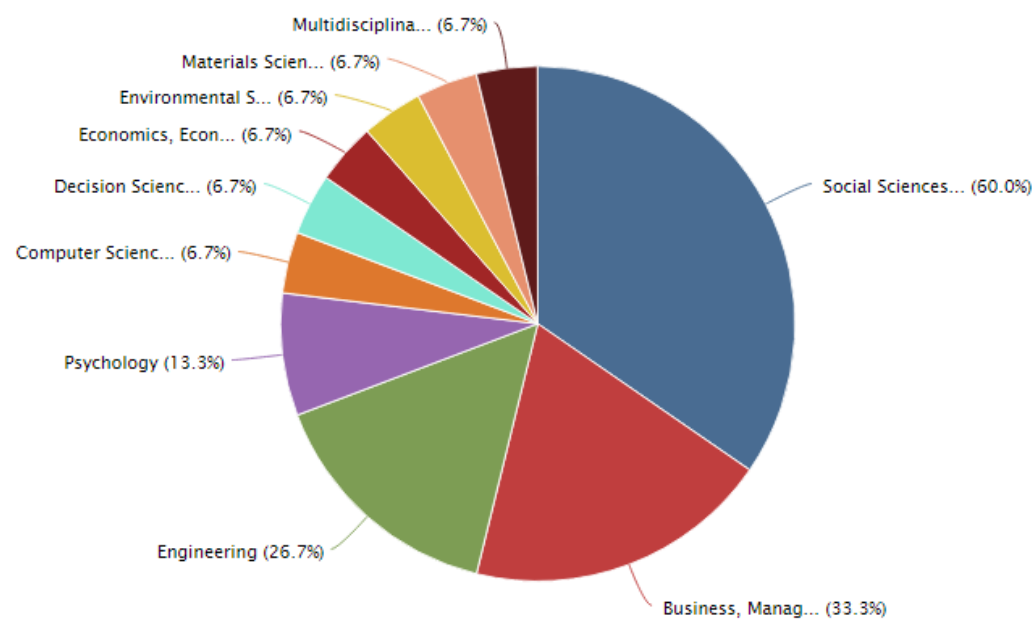

Gráfico 4 - Área de estudo

Fonte: Dados da pesquisa.

Conforme mostrado no Gráfico 5, a autora com maior produção sobre o tema pesquisado foi Alfiya Rafisovna Masalimova, com dois artigos publicados, um no ano de 2014 e outro em 2016, ambos em coautoria com outros colaboradores, e o artigo 'Distantin-Company Foreign Language Learning Involving Universitys Tudents-tutors', de 2014, foi o mais citado, apresentando 13 citações.

Documentos por autor

Compare as contagens de documentos para até 15 autores

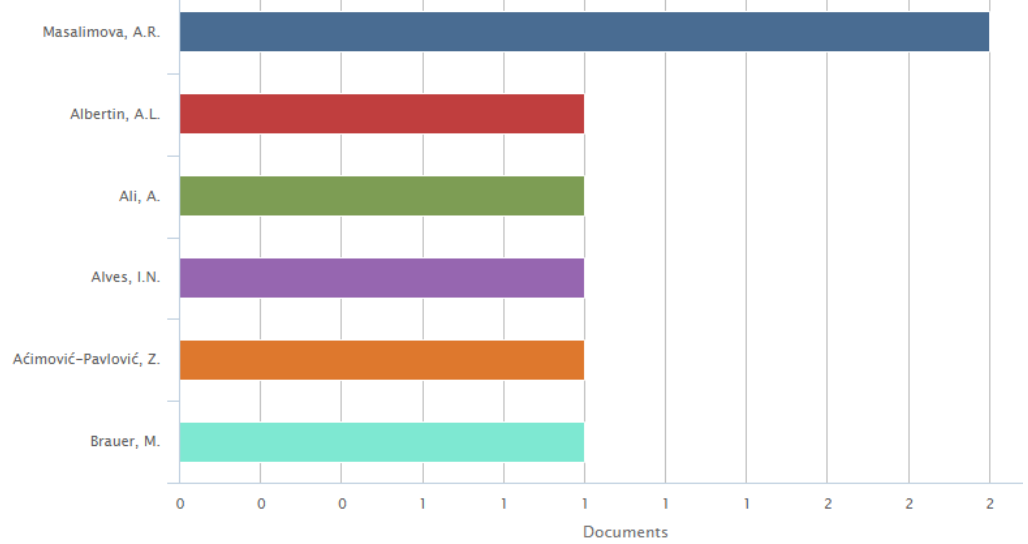

Gráfico 5 - Autores mais citados

Fonte: Dados da pesquisa. 
Ainda, ressalta-se a importância dos artigos selecionados, pois na base Scopus todas as publicações são revisadas por pares, o que representa um "mecanismo endossado pela comunidade científica e, mais recentemente, por outros setores da sociedade, como aquele que assegura a confiabilidade, qualidade e originalidade dos documentos" (NASSI-CALÒ, 2015, p. 1).

Os artigos identificados e avaliados, em atendimento ao escopo da pesquisa, estão descritos no Quadro 4, representando um total de 15 documentos. As discussões que seguem, nesta seção, explanam os recursos tecnológicos interativos, presentes nos artigos, com intuito de elucidar a sua aplicação na Educação Corporativa a Distância.

\begin{tabular}{|l|l|l|l|}
\hline Id & \multicolumn{1}{|c|}{ Autor(es) } & \multicolumn{1}{c|}{ Título } & Ano \\
\hline 1 & $\begin{array}{l}\text { KAPLAN, A. M.; } \\
\text { HAENLEIN, M. }\end{array}$ & $\begin{array}{l}\text { Higher education and the digital } \\
\text { revolution: about MOOCs, SPOCs, } \\
\text { social media, and the Cookie Monster }\end{array}$ & 2016 \\
\hline 2 & $\begin{array}{l}\text { MASALIMOVA, A. R.; } \\
\text { SHAIDULLINA, A. R. }\end{array}$ & $\begin{array}{l}\text { Study of international mentoring } \\
\text { and coaching practices and their } \\
\text { constructive application in the Russian } \\
\text { system of corporate education and } \\
\text { training }\end{array}$ & 2016 \\
\hline 3 & WILLIAMSON, B. & $\begin{array}{l}\text { Silicon startup schools: technocracy, } \\
\text { algorithmic imaginaries and venture } \\
\text { philanthropy in corporate education } \\
\text { reform }\end{array}$ & 2016 \\
\hline 4 & $\begin{array}{l}\text { MASALIMOVA, A. R .A; } \\
\text { IKRAMOVA, G. D. B.; } \\
\text { SHAIDULINA, A. R. B.; } \\
\text { GUBAIDULLINA, G. T. B.; } \\
\text { APRAKSINA, N. D. B. }\end{array}$ & $\begin{array}{l}\text { Distant in-company foreign language } \\
\text { learning involving university students- } \\
\text { tutors }\end{array}$ & 2014 \\
\hline 5 & $\begin{array}{l}\text { MORAIS, A. S. A.; NAUE, } \\
\text { G. S. A.; ARMSTRONG, } \\
\text { J. G. A.; WOEHL, S. } \\
\text { A.; MARTINS, P. F. A.; } \\
\text { CATAPAN, A. B. }\end{array}$ & $\begin{array}{l}\text { Perception of human resources sector } \\
\text { of a brazilian institution regarding } \\
\text { challenges to implementation of } \\
\text { corporate education }\end{array}$ & 2014 \\
\hline 6 & $\begin{array}{l}\text { ALI, A. } \\
\text { cornation }\end{array}$ & $\begin{array}{l}\text { Integrating corporate education } \\
\text { in Malaysian higher education: } \\
\text { the experience of Open University } \\
\text { Malaysia }\end{array}$ & 2013 \\
\hline
\end{tabular}




\begin{tabular}{|c|c|c|c|}
\hline Id & Autor(es) & Título & Ano \\
\hline 7 & $\begin{array}{l}\text { ALVES, I. N. A.; } \\
\text { SCORSOLINI-COMIN, F. B. }\end{array}$ & $\begin{array}{l}\text { The use of the wiki technology in } \\
\text { corporate education: contributions to } \\
\text { a debate }\end{array}$ & 2012 \\
\hline 8 & $\begin{array}{l}\text { MILOSAVLJEVIĆ, G. } \\
\text { A. TANASKOVIĆ, Z. B.; } \\
\text { AĆIMOVIĆ-PAVLOVIĆ, Z. } \\
\text { C. }\end{array}$ & $\begin{array}{l}\text { Strategic development in company } \\
\text { and e-education }\end{array}$ & 2012 \\
\hline 9 & $\begin{array}{l}\text { ALBERTIN, A. L. A.; } \\
\text { BRAUER, M. B. }\end{array}$ & $\begin{array}{l}\text { Distance education resistance in } \\
\text { corporate education }\end{array}$ & 2012 \\
\hline 10 & $\begin{array}{l}\text { LONDON, M. A.; HALL, } \\
\text { M. B. }\end{array}$ & $\begin{array}{l}\text { Unlocking the value of Web } 2.0 \\
\text { technologies for training and } \\
\text { development: the shift from } \\
\text { instructor-controlled, adaptive } \\
\text { learning to learner-driven, generative } \\
\text { learning }\end{array}$ & 2011 \\
\hline 11 & $\begin{array}{l}\text { SECUNDO, G.; GRIPPA, } \\
\text { F.; MAGGIO, M. D.; } \\
\text { VECCHIO, P. D. }\end{array}$ & $\begin{array}{l}\text { Design of a web } 2.0 \text { learning } \\
\text { laboratory for developing Managerial } \\
\text { Competencies }\end{array}$ & 2009 \\
\hline 12 & VASQUEZ BRONFMAN, S. & A heideggerian view on e-learning & 2008 \\
\hline 13 & $\begin{array}{l}\text { PANTOVIC, V. A.; } \\
\text { SAVKOVIC, M. A.; } \\
\text { STARCEVIC, D. B. }\end{array}$ & $\begin{array}{l}\text { Work in progress - virtual business } \\
\text { school and enterprise resource } \\
\text { planning system integration in } \\
\text { energorpojekt group }\end{array}$ & 2008 \\
\hline 14 & LIEN, M. & Lighting education with commercials & 2007 \\
\hline 15 & $\begin{array}{l}\text { DUFFY, T. M.; KIRKLEY, } \\
\text { J. R. }\end{array}$ & $\begin{array}{l}\text { Learner-centered theory and practice } \\
\text { in distance education: cases from } \\
\text { higher education }\end{array}$ & 2003 \\
\hline
\end{tabular}

Quadro 4 - Artigos relacionados à pesquisa

Fonte: Dados da pesquisa.

O primeiro documento, descrito no Quadro 4, é um artigo dos autores Andreas Kaplan e Michael Haenlein, e foi publicado na França, no ano de 2016. Essa investigação traz uma análise relacionada à aprendizagem a distância online com o uso de MOOCs (Cursos Online Abertos Massivos), que são de acesso livre. Esses tipos de cursos online permitem a participação ilimitada de usuários e, também, o uso do SPOC (Small Private Open Course), considerados aos pequenos grupos, como modelos que revolucionaram a educação corporativa. Para Bastos e Biagiotti $(2014$, p. 2) "MOOC é um conceito que vem se desenvolvendo 
no campo de ensino e em especial no formato de educação a distância”. Numa visão 'privada' está o SPOC, que oferece cursos online com número limitado de alunos.

O segundo documento destacado, no Quadro 4, é um artigo das autoras Alfiya R. Masalimova e Almira R. Shaidullina, publicado em 2016, na Rússia. As pesquisadoras identificaram experiências nacionais e estrangeiras de mentoria e coaching em educação e treinamento corporativo. $\mathrm{O}$ artigo considera as características de algumas técnicas utilizadas na orientação internacional e de treinamento com destaque para e-coaching. O e-coaching é uma forma de educação a distância mais voltada ao treinamento e formação pessoal, que é realizado pela internet, por meio de comunidades de práticas.

O terceiro documento identificado foi publicado no ano de 2016, pelo autor Ben Williamson, no Reino Unido. O artigo retrata o surgimento de quatro escolas de inicialização de estudantes na área da tecnologia, que é totalmente gerida por executivos e engenheiros de algumas das startups e empresas de web mais bem sucedidas do Vale do Silício. Segundo o autor supracitado, com esse perfil corporativo, as escolas se constituem em um poderoso "imaginário algorítmico" compartilhado que procura "perturbar" a escola pública através da expertise tecnocrática dos filantropos de risco do Vale do Silício. Um dos exemplos, citados por Williamson (2016), se baseia em Makerspaces, em um modelo de escola estabelecido por um ex-executivo do Google. As tecnologias dos Makerspaces proporcionam uma educação híbrida.

O quarto documento, mostrado no Quadro 4, é de autoria de Alfiya R. Masalimova, Gulnara D. Ikramova, Albina R. Shaidullina, Gulnisa T. Gubaidullina e Nina D. Apraksina, publicado na Rússia no ano de 2014. O artigo evidencia um estudo de caso, em que se destaca a tecnologia de treinamento na empresa para o desenvolvimento de aprendizagem de línguas estrangeiras de profissionais da indústria do petróleo, sugerindo que estudantes da universidade corporativa atuem como tutores e moderadores, envolvendo-se em fóruns online, de modo a atingir dois objetivos distintos, o primeiro é dirigido à formação de competências em línguas estrangeiras de especialistas das empresas e, o segundo, a melhorar a competência dos alunos.

O quinto documento é um artigo de autoria de Ariane D. S. Morais, Greicy S. Naue, Jéssica G. Armstrong, Sidele Woehl, Paulo F. Martins e Anderson Catapan, publicado no Brasil, no ano de 2014. Essa publicação tem como objetivo uma análise dos desafios e benefícios da Educação Corporativa, a fim de fortalecer a capacidade de organização com o desenvolvimento de programas alinhados ao planejamento estratégico da empresa. O estudo revela em seus resultados que se deve investir em educação a distância para se chegar aos objetivos de 
melhor controle e avaliação de resultados dos programas da Educação Corporativa, de maneira mais efetiva, abrangendo um número maior de funcionários, a partir do avanço tecnológico, da informação e do conhecimento.

O sexto documento identificado é um capítulo do livro Evolving Corporate Education Strategies for Developing Countries: The Role of Universities. O autor Anuwar Ali apresenta um relato das transformações da Educação Corporativa na Malásia, na qual as TIC permitem que muitas empresas possam abordar a educação e a formação continuada de seus funcionários, através de plataformas online e ferramentas baseadas na web. O autor supracitado identifica a Universidade Aberta da Malásia (OUM), desde o ano 2000, como a principal agente da introdução da EaD para a sociedade daquele país, presente também na EC, por meio de programas de educação corporativa para clientes locais e internacionais.

Seguindo, a ordenação do Quadro 4, o sétimo documento é um artigo publicado no Brasil, no ano de 2012, pelos autores Itamar N. Alves e Fábio Scorsolini-Comin. O trabalho teve como objetivo descrever um programa de treinamento baseado na tecnologia wiki, inserido nas práticas de educação corporativa em um banco brasileiro. A wiki permitiu o aperfeiçoamento das práticas de gestão do conhecimento, por meio da criação de comunidades virtuais de funcionários.

O oitavo documento é um artigo de autoria de Gordana D. Milosavljević, Zorica Tanasković, Zagorka S. Aćimović-Pavlović, no ano de 2012, na Sérvia. Esses autores avaliaram a utilização da e-educação (e-bibliotecas, ensino a distância, internet, intranet, entre outros) na Educação Corporativa, pois as pessoas estão se adaptando a novas tendências de refinamento de informações e também na transferência de conhecimento.

O nono documento também é um artigo, de autoria de Alberto Luiz Albertin e Marcus Brauer, publicado em 2012. O objetivo do estudo foi identificar e analisar as principais dimensões de resistência para Educação a Distância em Educação Corporativa. Os autores supracitados mostraram que, na amostra pesquisada, as dimensões "auteficácia" e "expectativa de desempenho" influenciam direta e positivamente a resistência à EAD na EC.

O décimo documento é um artigo de Manuel L. London e MJ Hall, publicado nos Estados Unidos, no ano de 2011. Nesse artigo, os autores analisam, através do estudo de dois casos, os processos de aprendizagem e capacidades da Web 2.0. As considerações dos autores sugerem que a Educação Corporativa na aprendizagem baseada na Web 2.0 deve incluir a utilização da tecnologia para rastrear e melhorar o aumento da aprendizagem, bem como discutem a mudança de papéis dos profissionais da aprendizagem que devem fornecer aprendizado 
adaptativo, estruturado e unilateral, para projetar e facilitar oportunidades de aprendizagem centrada no estudante, colaborativa e focada no problema.

Em seguida, o décimo primeiro documento é um artigo dos autores Giustina Secundo, Francesca Grippa, Marco D.Maggio e Pasquale Del Vecchio, publicado no ano de 2009, na Itália. Nesse trabalho, os autores descreveram o Laboratório de Aprendizagem Aplicada (ALL) como um modelo baseado numa abordagem centrada no aluno para o desenvolvimento de competências baseadas na tecnologia da web 2.0. A ALL é uma plataforma colaborativa que inclui blogs, wikis, Really Simple Syndication (RSS) e folksonomy e apoia a aprendizagem cooperativa, a aprendizagem baseada em projetos e a baseada em problemas.

O décimo segundo documento é uma publicação de autoria de Sergio Vasquez Bronfman, na França, no ano de 2008. O documento referido trata-se de um capítulo de livro cuja tradução literal para o português seria "Avanços em e-learning: experiências e metodologias” . O capítulo descrito introduz pensamentos do filósofo alemão Martin Heidegger e sugere como suas ideias podem ser aplicadas a um projeto de e-learning, podendo inspirar inovações em design e implementação e-learning, desse modo, colocando a prática no centro de criação de conhecimento, como situações reais ocorridas no caso da educação profissional e corporativa. O autor também aponta os limites do ensino a distância sob a perspectiva da natureza dos seres humanos.

O décimo terceiro documento avaliado, do tipo conference paper, foi publicado no ano de 2008 pelos autores Vladan Pantović, Marko Savković e Dušan B. Starčević, na Sérvia. Nessa publicação se forneceu uma descrição de um processo de redesenho de formação baseado na web clássica para o sistema de educação corporativa. Os principais dados obtidos utilizaram os resultados de testes online de empregados. Tais testes permitem feedback mais rápido dos funcionários que estão dispersos ao redor do mundo.

O décimo quarto documento é uma publicação de Mark Lien, no ano de 2007, nos Estados Unidos. O artigo apresenta tendências para moldar o futuro da educação corporativa, que incluem: unidades de educação continuada oferecidas para os programas educacionais baseados em produção, treinamento online, webcasts, webcasts interativos, apresentações de vídeo (live streaming) e apresentações de vídeo ao vivo interativas.

E o último documento, que consta no Quadro 4, é um livro com o título: Learner-centered theory and practice in distance education: cases from higher education, publicado em 2003, nos Estados Unidos. Os editores dessa obra são os americanos Thomas M. Duffy, e Jamie R. Kirkley que, junto com outros au- 
tores, abordam os mais diversos assuntos acerca da EaD, incluindo o tema Educação Corporativa a distância. $\mathrm{Na}$ obra, destaca-se a descrição de oito programas de educação a distância, que permitem aos leitores a compreensão de diferentes abordagens para o entendimento da prática pedagógica e das consequências da sua aplicação.

\section{CONSIDERAÇÕES FINAIS}

O estudo apresentou uma revisão sistemática sobre a Educação Corporativa a Distância, por meio de um levantamento das temáticas das ferramentas de apoio ao Ensino a Distância, na Educação Corporativa, através da técnica de bibliometria.

A combinação dos dados bibliométricos com a avaliação das publicações, na base selecionada, fornece informações relevantes para pesquisadores em Educação Corporativa a Distância, visto que as publicações identificadas indicam recursos e metodologias que favorecem esse tipo de prática.

As publicações selecionadas, em sua maioria, estavam relacionadas ao uso do e-learning como forma de treinamento coletivo, empresarial, o que possibilita o uso de diversas tecnologias como sala de bate-papo, links para fontes externas, vídeos, live streaming, entre outras, considerando metodologias em espaços como os ambientes virtuais e ambientes tecnológicos criativos como makerspaces.

Ainda verificou-se que a temática é interdisciplinar por estar presente em diferentes áreas de estudo, com destaque para área das Ciências Sociais e a de Negócios e Gestão. Como exemplo de países que tiveram mais publicações, destacam-se os Estados Unidos e o Brasil. A produção em sua maioria ocorreu nos anos de 2012 e encontra-se em crescimento, a partir do ano de 2016.

Como trabalhos futuros, sugere-se a continuação da pesquisa, considerando dados atuais e outras bases de dados de relevância, tais como a Scopus, que foi empregada neste estudo. Também é importante que as futuras pesquisas englobem os desafios encontrados pelas empresas na implantação da Educação Corporativa a distância, e que qualifiquem qual é a metodologia e/ou ferramenta de maior aceitação e/ou rejeição por parte dos colaboradores.

\section{REFERÊNCIAS}

ABREU, A. F.; GONÇALVES, C. M.; PAGNOZZI, L. Tecnologia da informação e educação corporativa: contribuições e desafios da modalidade de ensino-aprendizagem a distância no desenvolvimento de pessoas. Rev. Pec., Curitiba, v. 3, n. 1, p. 47-58, jul. 
2003.

ALENCAR, G. D. et.al. Educação corporativa em EAD: benefícios da modalidade e-learning. In: ENCONTRO DE ENSINO, PESQUISA E EXTENSÃO DA FACULDADE SENAC, 6., 2012, Recife. Anais... Recife: SENAC, 2012.

ALVES, I. N.; SCORSOLINI-COMIN, F. Utilização da tecnologia wiki na educação corporativa: contribuições para um debate. Revista Brasileira de Orientação Profissional, v. 13, n. 2, p. 209-222, dez. 2012.

BASTOS, R. C.; BIAGIOTTI, B. MOOCs: uma alternativa para a democratização do ensino. Revista RENOTE, v. 12, n. 1, p. 1-9, jul. 2014.

BOMFIM, L. S. S.; GONÇALVES, A. V. Escrita digital colaborativa a partir da tecnologia wiki. Revista Linguagem \& Ensino, v. 17, n. 3, p. 823-855, 2015.

BRASIL. Ministério do Desenvolvimento Indústria e Comércio Exterior. Educação corporativa. 2016. Disponível em: <http://www.desenvolvimento.gov.br/sitio/interna/interna.php?area=3\&menu=3599>. Acesso em: 22 ago. 2016.

CARVALHO, A. Reflexões sobre educação a distância no Brasil: questão social, qualidade e expansão. In: SEMINÁRIO INTERNACIONAL DE EDUCAÇÃO SUPERIOR, 2014, São Paulo. Anais... São Paulo. Disponível em: <https:/www.uniso.br/ publicacoes/anais_eletronicos/2014/2_es_politicas_publicas/02.pdf.> Acesso em: 7 set. 2016.

CASTRO, A. C.; VALENTE, G. S. C.; HUDIK, Y. A educação corporativa como vantagem competitiva sustentável para as empresas na atualidade. Revista Augustus, Rio de Janeiro, v. 16, n. 32, p. 40-54, jul. 2011.

D’ANDRÉA, C. Colaboração, edição, transparência: desafios e possibilidades de uma "wikificação” do jornalismo. Brazilian Journalism Research (versão em português), v. 5, n. 1, p. 1-17, 2009.

EBOLI, M. Educação corporativa no Brasil: mitos e verdades. São Paulo: Gente, 2004.

- Pesquisa Nacional de Práticas e Resultados em Educação Corporativa. São Paulo: Fundação Instituto de Administração, 2015. Disponível em: <http://www. abed.org.br/arquivos/Dia_Nacional_EaD_2015_Marisa_Eboli.pdf>. Acesso em: 7 set. 2016.

FERLA, L. A. Rede social corporativa: sua empresa ainda vai ter uma. 2012. Disponível em: <http://imasters.com.br/artigo/25255/tendencias/rede-socialcorporativa-sua-empresa-ainda-vai-ter-uma/>. Acesso em: 9 set. 2016.

FERNANDES, P. C. O e-learning como ferramenta estratégica para o treinamento e o desenvolvimento de pessoas e organizações. São Paulo: Associação Brasileira de Educação a Distância, 2013. Disponível em: <http:/www.abed.org.br/site/pt/midiateca/ textos_ead/1100/2013/04/http//www.abed.org.br/media/artigo_elearning.pdf >. Acesso em: 7 set. 2016.

FREIRE, P. S. Aumente a qualidade e quantidade de suas publicações científicas: manual para elaboração de projetos e artigos científicos. Curitiba: CRV, 2013. 
Compartilhamento do conbecimento interorganizacional: causas essenciais dos problemas de integração em fusões e aquisições. 2010149 f. Dissertação (Mestrado em Engenharia e Gestão do Conhecimento) - Centro Tecnológico, Universidade Federal de Santa Catarina - UFSC, 2010.

GULINI, A. S.; MISAGHI, M. Redes Sociais Corporativas: Avaliação da Centralidade de Grau Através de Índices Como Ferramenta de Gestão. Produção em Foco, v. 2, n. $1,2012$.

HACK, J. R. Introdução à educação a distância. Florianópolis: LLV/CCE/UFSC, 2011. .; RAMOS, F.; SANTOS, A. Digital Storytelling e formação corporativa: possibilidades para a aprendizagem de adultos. Comunicação \& Educação, São Paulo, v. 18, n. 1, p. 15-23, jan./jun. 2013.

NASSI-CALÒ, L. Avaliação por pares: ruim com ela, pior sem ela [online]. SciELO em Perspectiva, 2015. Disponível em: <https://blog.scielo.org/blog/2015/04/17/avaliacao-por-pares-ruim-com-ela-pior-sem-ela/>. Acesso em: ago. 2016.

LIMA, A. A. Fundamentos e práticas na EaD. ed. rev. e atual. Cuiabá: UFMG/ Rede e-Tec Brasil, 2012.

MARTINS, H. G. Estudos da trajetória das universidades corporativas brasileiras. 2004. Tese (Doutorado em Engenharia de Produção) - Universidade Federal do Rio de Janeiro, Rio de Janeiro, 2004.

MEISTER, J. Educação corporativa. São Paulo: Makron Books, 1999.

MONTEIRO, F. R.; MÜRI, L. V. M. Educação corporativa: um estudo exploratório sobre a contribuição da tecnologia na capacitação de pessoas. 2014. $90 \mathrm{f}$. Trabalho de Conclusão de Curso (Graduação em Engenharia de Produção) - Escola Politécnica, Universidade Federal do Rio de Janeiro, Rio de Janeiro, 2014.

QUARTIERO, E. M.; CERNY, R. Z. Universidade Corporativa: uma nova face da relação entre mundo do trabalho e mundo da educação. In: QUARTIERO, E. M. \& BIANCHETTI, L. (Org.). Educação corporativa: mundo do trabalho e do conbecimento: aproximações. São Paulo: Cortez, 2005.

REIS, G. G.; SILVA, L. M. T.; EBOLI, M. P. A prática reflexiva e suas contribuições para a educação corporativa. REGE Revista de Gestão, v. 17, n. 4, p. 403-419, out./dez. 2010.

ROBIN, B. What is Digital Storytelling? 2004. Disponível em: <http://digitalstorytelling. coe.uh.edu/index.cfm>. Acesso em: 8 set. 2016.

SILVA, M. R.; HAYASHI, C. R. M.; HAYASHI, M. C. P. I. Análise bibliométrica e cientométrica: desafios para os especialistas que atuam no campo. Incid: $R$. Ci. Inf. e Doc., Ribeirão Preto, v. 2, n. 1, p.110-129, jun. 2011.

SILVA, N. P. O impacto da implantação da educação corporativa à distância (ECAD) na Companhia Paranaense de Energia - COPEL. 2010. 135 f. Dissertação (Mestrado em Engenharia de Produção) - Universidade Tecnológica Federal do Paraná, Ponta Grossa, 2010. 
